\title{
Wind Energy Systems and Power Quality: Matrix versus Two-Level Converters
}

\author{
R. Melício ${ }^{1}$, V.M.F. Mendes ${ }^{2}$ and J.P.S. Catalão ${ }^{1}$ \\ ${ }^{1}$ University of Beira Interior \\ Covilhã, Portugal \\ e-mail: ruimelicio@gmail.com, catalao@ubi.pt \\ ${ }^{2}$ Instituto Superior de Engenharia de Lisboa \\ Lisbon, Portugal \\ e-mail: vfmendes@isel.pt
}

\begin{abstract}
This paper presents data of the actual installed electric power capacity for the renewable energy power systems in Portugal. Also, this paper presents a contribution consisting in a modulation strategy for simulation of a wind energy system with different topologies for power converters, consisting on a matrix and a two-level converter. Although more complex, this modulation strategy is justified for more accurate results.
\end{abstract}

\section{Key words}

Wind energy systems, power quality, power electronics, modelling and simulation.

\section{Introduction}

Electricity restructuring has offered to us additional flexibility at both level of generation and consumption. Also, since restructuring has strike the power system sector, developments in distributed generation technologies opened new perspectives for generating companies [1], in order to consider their energy supply portfolio with adequacy and advantage. Adequacy and advantage due to a better generation mix, concerning not only the traditional economic perspective, but also politic developments with strong social impact in power systems, imposing the internalization of costs formerly externalized. Distributed generation technology is said to offer a clean energy source with fast ramp capability, and it goes on penetrating more and more power systems. Distributed generation technology includes, for instances, arrays of solar photovoltaic panels, wind farms, hydroelectric, biomass and tidal power plants. Among distributed generation technology, wind farms are the most commonly viewed on power systems, even envisaged as competing with the traditional fossil-fuelled thermal power plants in the near future.

The European Commission concerned with the climate change, due to the emission of greenhouse gases, put forward a set of proposals to create a new Energy Policy for Europe, cutting its own $\mathrm{CO}_{2}$ emissions by at least $20 \%$ by 2020 and $50 \%$ until 2050 , increasing the share of renewable energy sources in the overall generation mix. Hence, it is expected that wind energy will turn out to be an important part of the Energy Policy for Europe. In Portugal, the total installed wind power capacity reached 2037 MW in September 2007, and continues growing.

The increasing share of wind in power generation will change considerably the dynamic behaviour of the power system [2], and may lead to a new strategy for power system frequency regulation in order to avoid degradation of frequency quality [3]. Hence, network operators have to ensure that consumer power quality is not compromised [4]. New technical challenges emerge due to increased wind power penetration, dynamic stability and power quality, implying research of more realistic physical models for wind energy systems. Power electronic converters have been developed for integrating wind power with the electrical grid. The use of power electronic converters allows for variable speed operation of the wind turbine and enhancement in power extraction. In variable speed operation, a control method designed to extract maximum power from the turbine and provide constant grid voltage and frequency is required [5].

This paper is concerned with modelling and simulation in Matlab/Simulink of a wind energy system with different topologies for the power converters, namely a matrix converter and a two-level converter. We use pulse modulation by space vector modulation associated with sliding mode for controlling the converters. We introduce power factor control at the output of the converters. Also, we present the harmonic behaviour for the current injected in the electric network, in steady-state simulation, using the Fast Fourier Transform, FFT [6]. Finally, we present the electric behaviour for the power and the current at the output of the converters.

\section{Turbine and Electric Machine}

The mechanical power of the turbine is given by:

$P_{m}=\frac{1}{2} \rho A u^{3} c_{p}$ 
where $P_{m}$ is the power extracted from the airflow, $\rho$ is the air density, $A$ is the area covered by the rotor, $u$ is the wind speed upstream of the rotor, and $c_{p}$ is the performance coefficient or power coefficient. The power coefficient is a function of the pitch angle of rotor blades $\theta$ and of the tip speed ratio $\lambda$, which is the ratio between blade tip speed and wind speed upstream of the rotor. The computation of the power coefficient requires the use of blade element theory and the knowledge of blade geometry. We consider the blade geometry using the numerical approximation developed in [7], assuming that the power coefficient is given by:

$$
c_{p}=0.73 \lambda_{i} e^{-\frac{18.4}{\lambda_{i i}}}
$$

where $\lambda_{i}$ and $\lambda_{i i}$ are respectively given by:

$$
\begin{aligned}
& \lambda_{i}=\frac{151}{\lambda_{i i}}-0.58 \theta-0.002 \theta^{2.14}-13.2 \\
& \lambda_{i i}=\frac{1}{\frac{1}{(\lambda-0.02 \theta)}-\frac{0.003}{\left(\theta^{3}+1\right)}}
\end{aligned}
$$

The maximum power coefficient is given for a null pitch angle and is equal to:

$c_{p_{\max }}=0.4412$

where the optimum tip speed ratio is equal to:

$\lambda_{\text {opt }}=7.057$

The power coefficient is illustrated in Figure 1 as a function of the tip speed ratio.

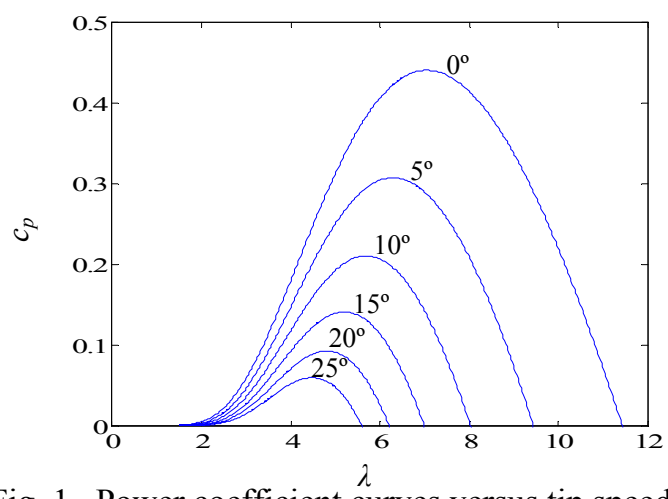

Fig. 1. Power coefficient curves versus tip speed ratio

The mechanical power extracted from the wind is modelled by (1) to (4). The equations for modelling rotor motion are given by:

$$
\begin{aligned}
& \frac{d \omega_{m}}{d t}=\frac{1}{J_{m}}\left(T_{m}-T_{d m}-T_{a m}-T_{\text {elas }}\right) \\
& \frac{d \omega_{e}}{d t}=\frac{1}{J_{e}}\left(T_{\text {elas }}-T_{d e}-T_{a e}-T_{e}\right)
\end{aligned}
$$

where $\omega_{m}$ is the rotor speed of turbine, $J_{m}$ is turbine moment of inertia, $T_{m}$ is the mechanical torque, $T_{d m}$ is the resistant torque in the turbine bearing, $T_{a m}$ is the resistant torque in the hub and blades due to the viscosity of the airflow, $T_{\text {elas }}$ is the torque of the torsional stiffness, $\omega_{e}$ is the rotor speed of the electric machine, $J_{e}$ is the electric machine moment of inertia, $T_{d e}$ is the resistant torque in electric machine bearing, $T_{a e}$ is the resistant torque due to the viscosity of the airflow in the electric machine, and $T_{e}$ is the electric torque. The equations for modelling a permanent magnetic synchronous machine, PMSM, can be found in diverse literature; using the motor machine convention, the following set of equations [8] is considered:

$$
\begin{aligned}
& \frac{d i_{d}}{d t}=\frac{1}{L_{d}}\left(u_{d}+p \omega_{e} L_{q} i_{q}-R_{d} i_{d}\right) \\
& \frac{d i_{q}}{d t}=\frac{1}{L_{q}}\left[u_{q}-p \omega_{e}\left(L_{d} i_{d}+M i_{f}\right)-R_{q} i_{q}\right]
\end{aligned}
$$

where $i_{f}$ is the equivalent rotor current, $M$ is the mutual inductance, $p$ is the number of pairs of poles; and where in $d q$ axes $i_{d}$ and $i_{q}$ are the stator currents, $L_{d}$ and $L_{q}$ are the stator inductances, $R_{d}$ and $R_{q}$ are the stator resistances, $u_{d}$ and $u_{q}$ are the stator voltages. A unity power factor is imposed to the electric machine, implying a null $Q_{e}$. The electric power $P_{e}$ is given by:

$$
P_{e}=\left[\begin{array}{lll}
u_{d} & u_{q} & u_{f}
\end{array}\right]\left[\begin{array}{lll}
i_{d} & i_{q} & i_{f}
\end{array}\right]^{T}
$$

The output power injected in the electric network characterized by $\mathrm{P}$ and $\mathrm{Q}$ in $\alpha \beta$ axes [9] is given by:

$\left[\begin{array}{l}P \\ Q\end{array}\right]=\left[\begin{array}{cc}u_{\alpha} & u_{\beta} \\ -u_{\beta} & u_{\alpha}\end{array}\right]\left[\begin{array}{l}i_{\alpha} \\ i_{\beta}\end{array}\right]$

where in $\alpha \beta$ axes, $i_{\alpha}$ and $i_{\beta}$ are the phase currents, $u_{\alpha}$ and $u_{\beta}$ are the phase voltages. The apparent output power [9] is given by:

$S=\left(P^{2}+Q^{2}+H^{2}\right)^{1 / 2}$

where $\mathrm{H}$ is the harmonic power.

\section{Matrix Converter}

The matrix converter is an $\mathrm{AC} / \mathrm{AC}$ converter, with nine bidirectional commanded IGBT's $S_{i j}$. It is connected between the electric machine and a second order filter, which in turn is connected to an electric network. The second order filter is an inductive load that avoids the interruption of the output currents. A three-phase active symmetrical circuit in series models the electric network. For the matrix converter modelling we assumed that: 1) the diodes are ideal: in conduction it is null the voltage between its terminals, and in blockade it is null the current that passes through it; 2) the elements of the command matrix of the converter are bidirectional switches in voltage and current; 3) the command variables $S_{i j}$ for each $i$ has for one $j$ the value one, i.e., only one switch is in conduction in order to achieve continuity in the current in each phase; 4) the command variables $S_{i j}$ for each $j$ has for one $i$ the value one, i.e., only one switch is in conduction in order to achieve continuity in the voltage between the phases [10]. The configuration of the system that will be simulated is shown in Figure 2.

The IGBT's commands $S_{i j}$ are given in function of the on and off states as follows: 


$$
S_{i j}=\left\{\begin{array}{l}
1, \text { (on }) \\
0,(\text { off })
\end{array} ; \quad i, j \in\{1,2,3\}\right.
$$

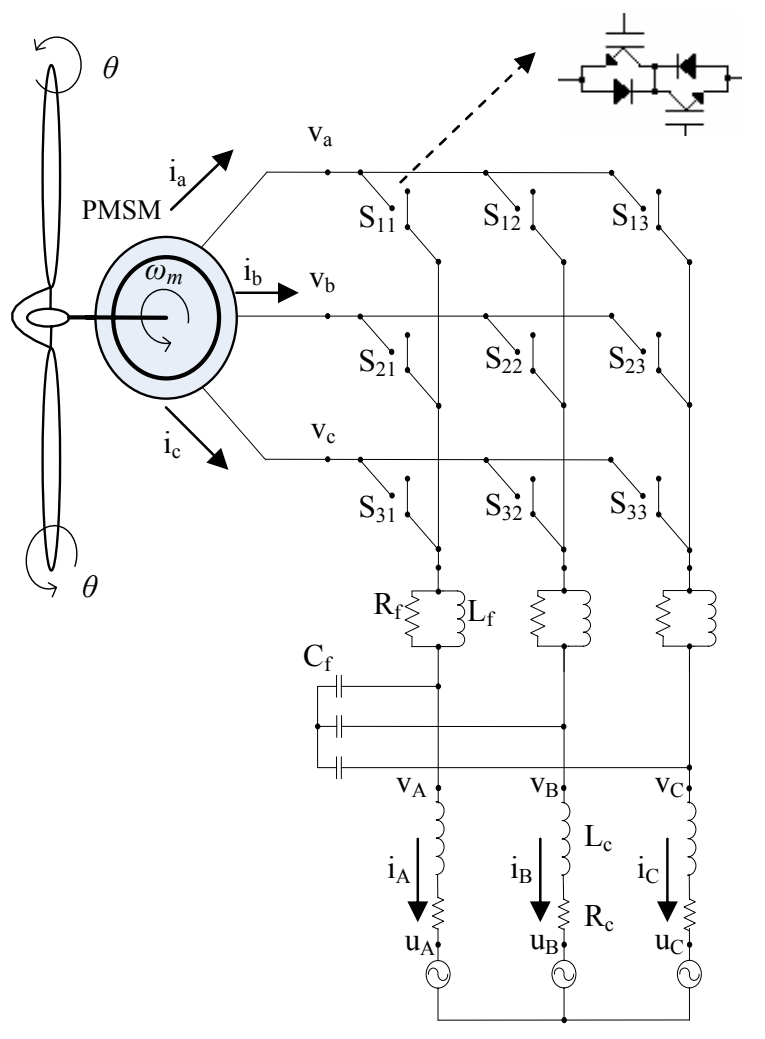

Fig. 2. Wind energy system with matrix converter

The assumptions in 3) and 4) are given by restrictions (15) on commands $S_{i j}$ : $\sum_{j=1}^{3} S_{i j}=1 \quad$ with $\quad i \in\{1,2,3\}$

$\sum_{i=1}^{3} S_{i j}=1 \quad$ with $\quad j \in\{1,2,3\}$

The vector of output phase voltages is related to the vector of input phase voltages through the command matrix, as follows:

$\left[\begin{array}{l}v_{A} \\ v_{B} \\ v_{C}\end{array}\right]=\left[\begin{array}{lll}S_{11} & S_{12} & S_{13} \\ S_{21} & S_{22} & S_{23} \\ S_{31} & S_{32} & S_{33}\end{array}\right]\left[\begin{array}{c}v_{a} \\ v_{b} \\ v_{c}\end{array}\right]=[S]\left[\begin{array}{c}v_{a} \\ v_{b} \\ v_{c}\end{array}\right]$

The vector of input phase currents is related to the vector of output phase currents through the command matrix, as follows:

$\left[\begin{array}{lll}i_{a} & i_{b} & i_{c}\end{array}\right]^{T}=[S]^{T}\left[\begin{array}{lll}i_{A} & i_{B} & i_{C}\end{array}\right]^{T}$

Hence, (14) to (17) model the matrix converter.

\section{Two-Level Converter}

The two-level converter is an $\mathrm{AC} / \mathrm{DC} / \mathrm{AC}$ converter, with six unidirectional commanded IGBT's $S_{i k}$, used as a rectifier, and with the same number of IGBT's, used as an inverter. The rectifier is connected between an electric machine and a capacity bank. The inverter is connected between this capacity bank and a filter, which in turn is connected to an electric network. A three-phase symmetrical circuit in series models the electric network. The configuration of the system that will be simulated is shown in Figure 3.

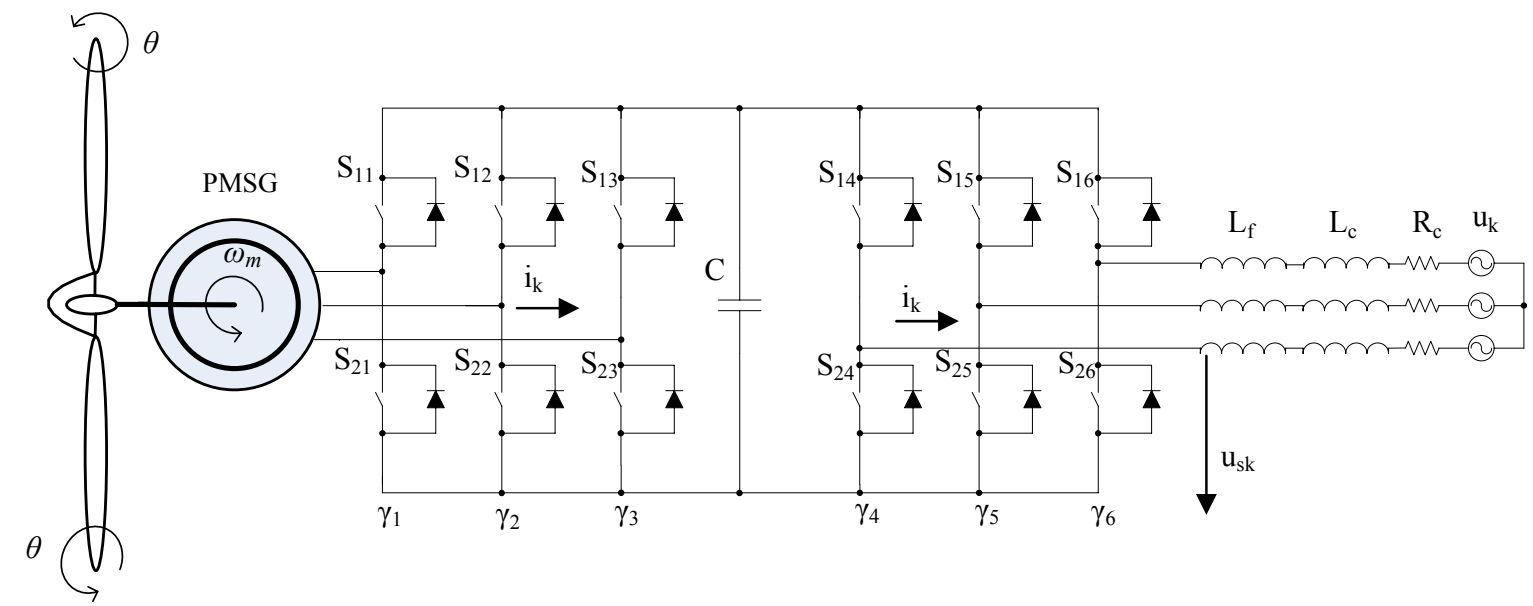

Fig. 3. Wind energy system with two-level converter

The groups of two IGBT's linked to the same phase constitute a leg $k$ of the converter. For the two-level converter modelling we assumed that: 1) The IGBT's are ideal and unidirectional, and they will never be subject to inverse voltages, being this situation guaranteed by the arrangement of connection in antiparallel diodes; 2) The diodes are ideal: in conduction it is null the voltage between its terminals and in blockade it is null the current that passes through it; 3) The continuous voltage in the exit of the rectifier should always be $v_{d c}>0$; 4) Each leg $k$ of the converter should always have one IGBT in conduction. For the switching function of each IGBT, the switching variable $\gamma_{k}$ is used to identify the state of the IGBT $i$ in the leg $k$ of the converter. The index $i$ with $i \in\{1,2\}$ identifies the IGBT. The index $k$ with $k \in\{1,2,3\}$ identifies the leg for the rectifier and $k \in\{4,5,6\}$ identifies the leg for the inverter. The two valid conditions for the switching variable of each leg $k$ are as follows: 
$\gamma_{k}=\left\{\begin{array}{ll}1, & S_{i k}=1 \\ 0, & S_{i k}=1\end{array}\right.$ for $\quad i \in\{1,2\} \quad$ and $\quad k \in\{1, \ldots, 6\}$

The topological restriction for the leg $k$ is given by:

$\sum_{i=1}^{2} S_{i k}=1 \quad k \in\{1, \ldots, 6\}$

Hence, each switching variable depends on the conduction and blockade states of the IGBT's. The phase currents injected in the electric network are modelled by the state equation:

$\frac{d i_{k}}{d t}=\frac{1}{\left(L_{c}+L_{f}\right)}\left(u_{k}-R_{c} i_{k}-u_{s k}\right) \quad k=\{4,5,6\}$

The output continuous voltage of the rectifier is modelled by the state equation:

$\frac{d v_{d c}}{d t}=\frac{1}{C}\left(\sum_{k=1}^{3} \gamma_{k} i_{k}-\sum_{k=4}^{6} \gamma_{k} i_{k}\right)$

Hence, (18) to (21) model the two-level converter.

\section{Control Method}

The controllers used in the converters are PI controllers. Pulse modulation by space vector modulation associated with sliding mode is used for controlling the converters. The converters are variable structure, because of the on/off switching of their IGBT's. Hence, the sliding mode control is important for controlling the converters, by guaranteeing the choice of the most appropriate space vectors. The power semiconductors present physical limitations, since they cannot switch with an infinite frequency. Thus, for a considered value of the switching frequency, an error $e_{\alpha \beta}$ will exist between the reference value and the control value. In order to guarantee that the system slides along the sliding surface $S\left(e_{\alpha \beta}, t\right)$, it is necessary to guarantee that the state trajectory near the surfaces verifies the stability conditions [10] given by:

$S\left(e_{\alpha \beta}, t\right) \frac{d S\left(e_{\alpha \beta}, t\right)}{d t}<0$

As power semiconductors can switch only at finite frequency, in practice a small error $\varepsilon>0$ for $S\left(e_{\alpha \beta}, t\right)$ is allowed. Hence, a switching strategy has to be considered. We consider one given by:

$-\varepsilon<S\left(e_{\alpha \beta}, t\right)<+\varepsilon$

A practical implementation of the switching strategy considered in (23) could be accomplished using hysteresis comparators.

The output voltages of matrix converter are switched discontinue variables. Therefore, if high enough switching frequencies are considered (much higher than the input and output matrix converter fundamental frequencies), it is possible to assume that in each switching period $T_{s}$, the average values of the output voltages are nearly equal to their reference average values, given by:

$\frac{1}{T_{s}} \int_{n T_{s}}^{(n+1) T_{s}}\left(v_{\alpha \beta}^{*}-v_{\alpha \beta}\right) d t=0$
The output voltage vectors in the $\alpha \beta$ plane for the matrix converter are shown in Figure 4.

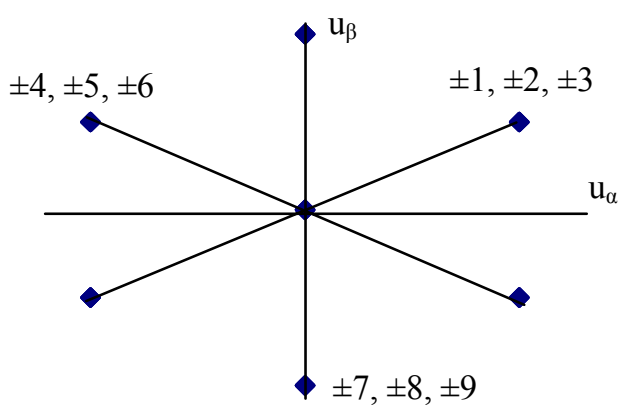

Fig. 4. Output voltage vectors for the matrix converter

The input phase current vectors in the $\alpha \beta$ plane for the matrix converter are shown in Figure 5.

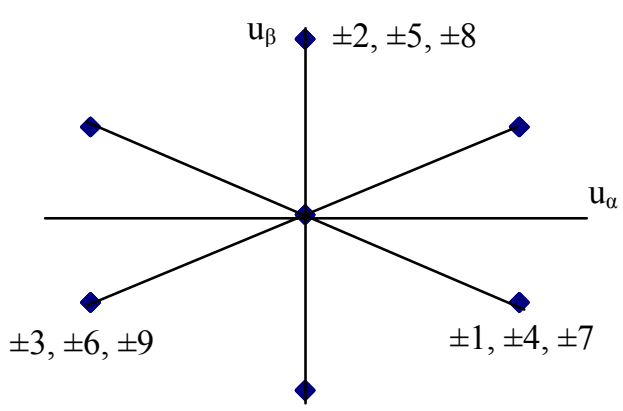

Fig. 5. Input phase current vectors, matrix converter

The output voltage vectors in the $\alpha \beta$ coordinates for the two-level converter are shown in the Figure 6.

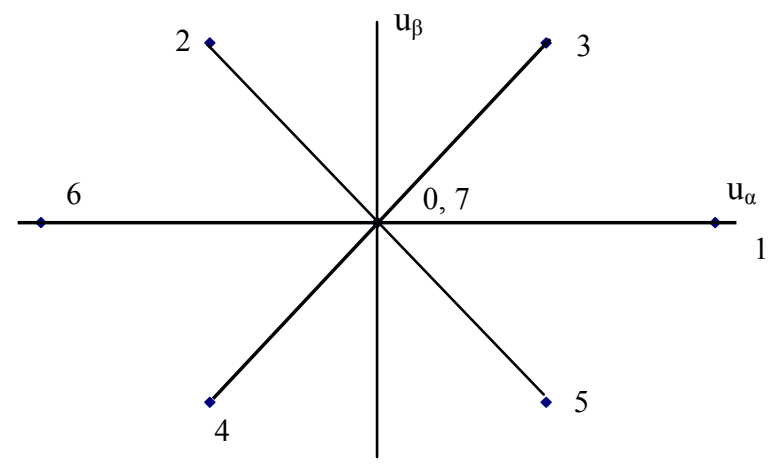

Fig. 6. Output voltage vectors for the two-level converter

\section{Simulation Results}

Two mathematical simulations carried out in Matlab/Simulink are reported: respectively for a matrix and for a two-level converter. The electric power of the wind energy system is $900 \mathrm{~kW}$ in both simulations. Also, the input for the wind speed upstream on the rotor is ramp shaped in both simulations, with speed between 4.5 and $25 \mathrm{~m} / \mathrm{s}$ during a time horizon of $3.5 \mathrm{~s}$. 
Figure 7 shows the mechanical power of the turbine and the electric power of the electric machine in both simulations.

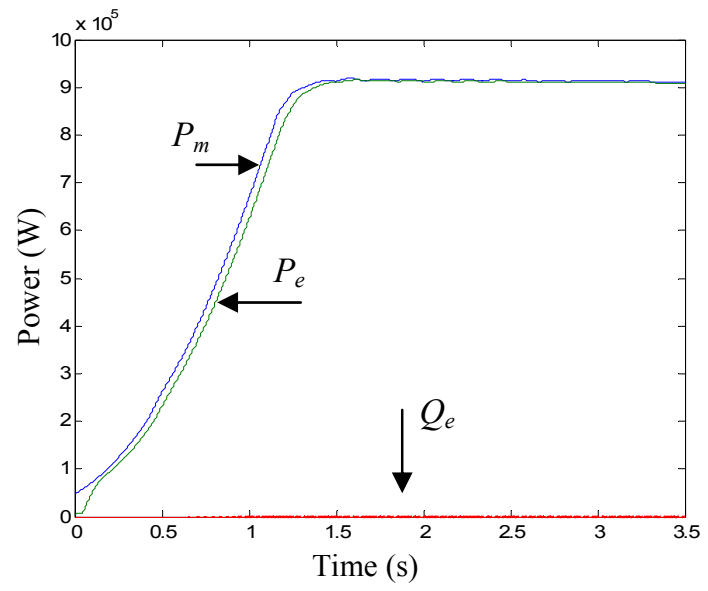

Fig. 7. Mechanical power and electric power

The output power injected in the electric network characterized by S, P and Q for the matrix converter is shown in Figure 8.

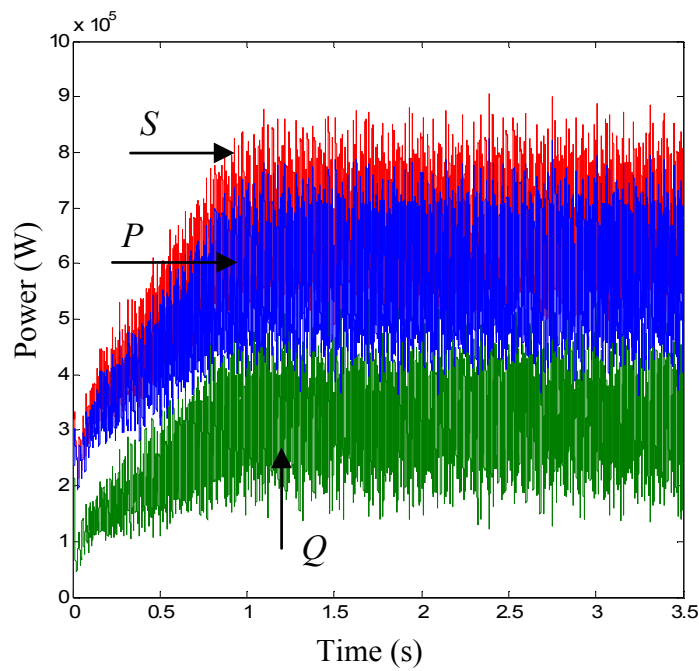

Fig. 8. Output power for the matrix converter

The current injected in the electric network for the matrix converter is shown in Figure 9.

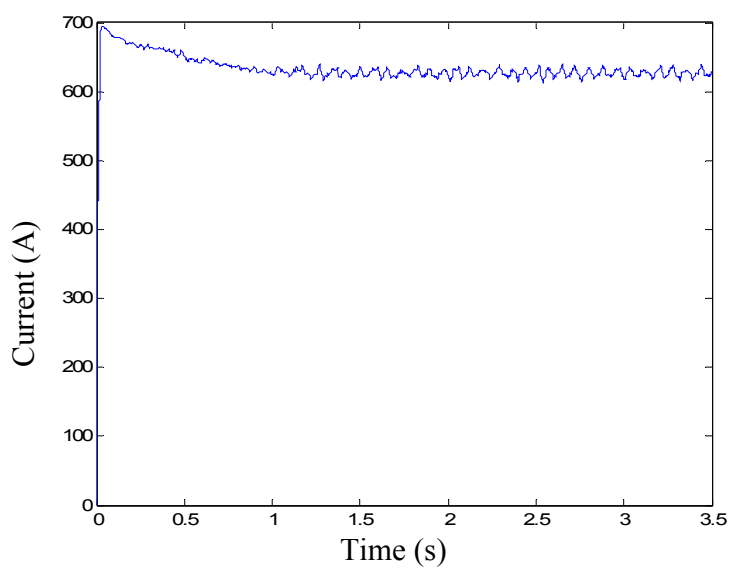

Fig. 9. Output current for the matrix converter
The harmonic behaviour computed by the FFT, for the current injected in the electric network for the matrix converter, is shown in Figure 10.

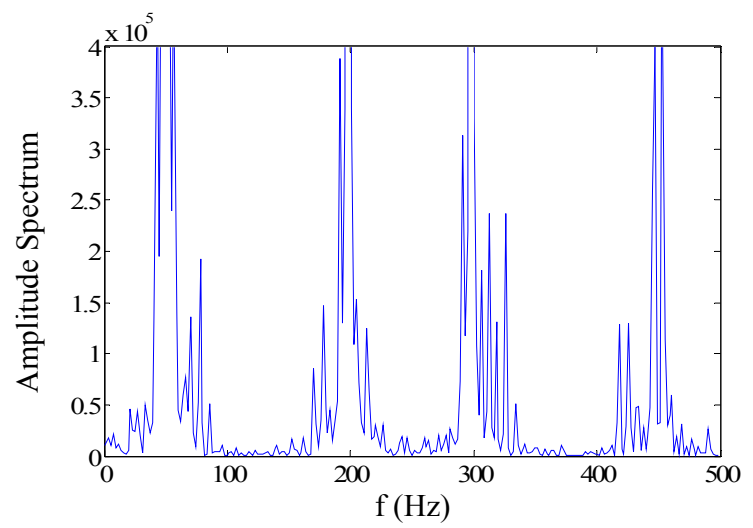

Fig. 10. The harmonic behaviour for the current for the matrix converter

The output power injected in the electric network characterized by S, P and Q for the two-level converter is shown in Figure 11.

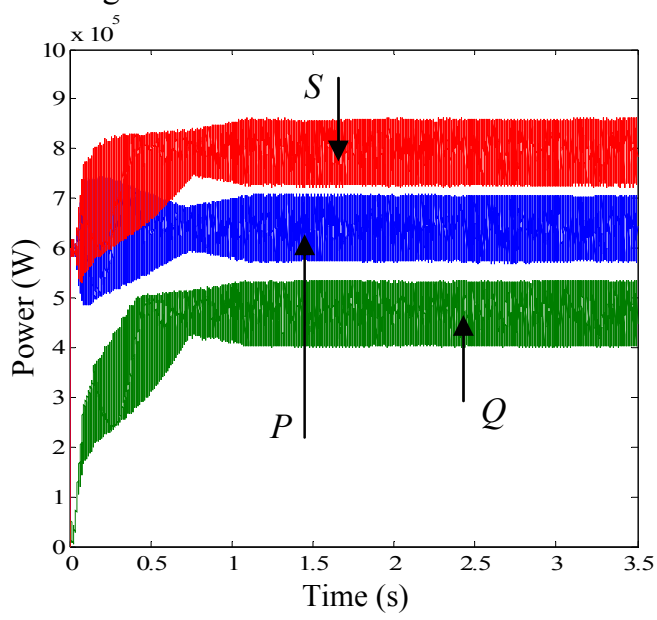

Fig. 11. Output power for the two-level converter

The current injected in the electric network for the two-level converter is shown in Figure 12.

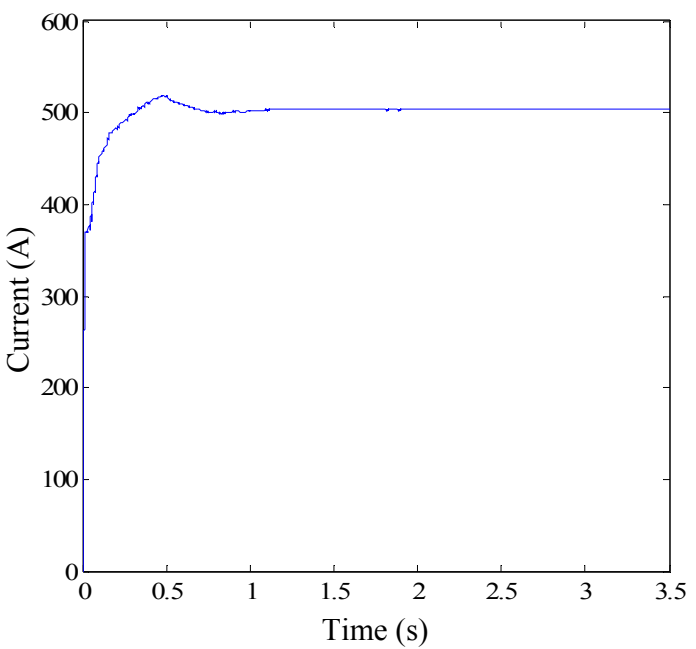

Fig. 12. Output current for the two-level converter 
The harmonic behaviour computed by the FFT, for the current injected in the electric network for the two-level converter, is shown in Figure 13.

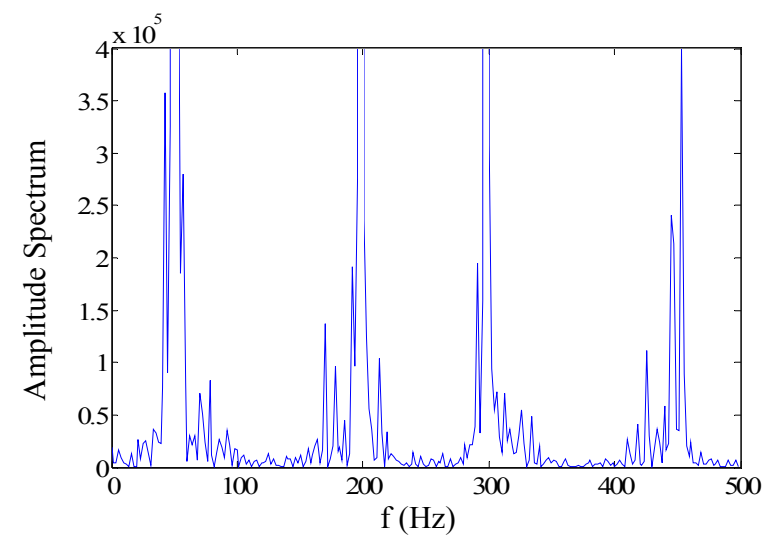

Fig. 13. The harmonic behaviour for the current for the two-level converter

\section{Conclusion}

The increased wind power penetration in power systems networks leads to new technical challenges, implying research of more realistic physical models for wind energy systems. This paper presents a more realistic modelling, considering a better accurate dynamic of the wind turbine, rotor modelling, generator, converter and a filter connecting the system to the network. A case study using Matlab/Simulink is presented for two power converter topologies integrating wind power with the electrical grid: two-level and matrix converters. Pulse modulation by space vector modulation associated with sliding mode is used for controlling the converters, and power factor control is used at the output of the converters. Also, we present the harmonic behaviour for the current injected in the electric network, in steadystate simulation, using FFT. The results show that the two-level converter has an enhanced behaviour comparatively to the matrix converter.

\section{References}

[1] J. A. Peças Lopes et al., "Integrating distributed generation into electric power systems: a review of drivers, challenges and opportunities", Electric Power Systems Research, Vol. 77, No. 9, pp 11891203, July 2007.

[2] I. Erlich et al., "Modeling of wind turbines based on doubly-fed induction generators for power system stability studies", IEEE Trans. On Power Systems, Vol. 3, No. 3, pp 909-919, August 2007.

[3] R. G. de Almeida and J. A. Peças Lopes, "Participation of doubly fed induction wind generators in system frequency regulation", IEEE Trans. On Power Systems, Vol. 22, No. 3, pp 944950, August 2007.

[4] J. M. Carrasco et al., "Power-electronic systems for the grid integration of renewable energy sources: a survey", IEEE Trans. On Industrial Electronics, Vol. 53, No. 4, pp 1002-1016, August 2006.

[5] J. A. Baroudi, V. Dinavahi and A. M. Knight, "A review of power converter topologies for wind generators", Renewable Energy, Vol. 32, No. 14, pp 2369-2385, November 2007.

[6] A. V. Oppenheim et al., Discrete-Time Signal Processing, 2nd edition, Prentice-Hall, 1999, Upper Saddle River, NJ.

[7] J. G. Slootweg, H. Polinder and W. L. Kling, "Representing wind turbine electrical generating systems in fundamental frequency simulations" IEEE Trans. On Energy Conversion, Vol. 18, No. 4, pp 516-524, December 2003.

[8] C. -M. Ong, Dynamic Simulation of Electric Machinery. New Jersey: Prentice Hall, 1998.

[9] E. H. Watanabe, R. M. Stephan and M. Aredes, "New concepts of instantaneous active and reactive powers in electrical systems with generic loads", IEEE Trans. On Power Delivery, Vol. 8, No. 2, pp. 697-703, April 1993.

[10] S. Pinto and J. Silva, "Sliding mode direct control of matrix converters", IET Electric Power Applications, Vol. 1, No. 3, pp 439-448, May 2007. 